\title{
Achlya mitochondrial DNA: gene localization and analysis of inverted repeats
}

\author{
Deborah S. Shumard *, Lawrence I. Grossman**, and Michael E. S. Hudspeth * \\ Department of Cellular and Molecular Biology, Division of Biological Sciences, The University of Michigan, \\ Ann Arbor, MI 48109, USA
}

\begin{abstract}
Summary. Mitochondrial DNA from four strains of the oomycete Achlya has been compared and nine gene loci mapped, including that of the ribosomal protein gene, varl. Examination of the restriction enzyme site maps showed the presence of four insertions relative to a map common to all four strains. All the insertions were found in close proximity to genic regions. The four strains also contained the inverted repeat first observed in $A$. ambisexualis (Hudspeth et al. 1983), allowing an examination by analysis of retained restriction sites of the evolutionary stability of repeated DNA sequences relative to single copy sequences. Although the inverted repeat is significantly more stable than single copy sequences, more detailed analysis indicates that this stability is limited to the portion encoding the ribosomal RNA genes. Thus, the apparent evolutionary stability of the repeat does not appear to derive from the inverted repeat structure per se.
\end{abstract}

Key words: Achlya - Mitochondrial DNA - Inverted repeat - Gene localization

\section{Introduction}

Present knowledge of the organization and expression of the mitochondrial genomes of the fungi and their allies is primarily derived from the ascomycetes. Studies of these organisms have demonstrated a five-fold variation in genome size (c.f. Clark-Walker et al. $1981 \mathrm{a}$ vs. Garber and Yoder 1984), a diversity in mitochondrially encoded genes c.f. Macino and Tzagoloff 1979 vs. Sebald et al. 1979), highly variable gene orders (Dujon 1983), and differences in the genetic code (c.f. Browning and RajBhandary 1982 vs. Bonitz et al. 1980; Hudspeth et al. 1982). In non-asco-

\footnotetext{
* Present addresses: Plant Molecular Biology Center, Department of Biological Sciences, Northern Illinois University, DeKalb, IL 60115-2861, USA

** Present address: Science 1333 H Street N.W., Washington DC 20005, USA

Abbreviations. ATPase 6, 9: genes for ATPase subunits 6 and 9; COI, II, III: genes for cytochrome oxidase subunits 1, 2, and 3; COB: gene for apocytochrome $b$; L-, S-RNA: genes for the mitochondrial large and small ribosomal RNAs; mtDNA: mitochondrial DNA; var1: gene for the $S$. cerevisiae mitochondrially encoded ribosomal protein; m.u.: map units; bp: base pairs; kb: kilobase pairs

Offprint requests to: $\mathrm{M}$. E. S. Hudspeth
}

mycete classes, however, information is limited to the diversity of genome sizes in basidiomycetes (e.g. Specht et al. 1983; Hintz et al. 1985) and restriction endonuclease maps for the myxomycete Physarum (Kawano et al. 1982) and the oomycetes Achlya and Phytophthora (Hudspeth et al. 1983; Boyd et al. 1984; Klimczak and Prell 1984).

Our previous studies of Achlya mtDNA revealed the presence of a large inverted repeat in the $50 \mathrm{~kb}$ circular genome. Although typical of chloroplast DNAs (Palmer 1985), large inverted repeats have been found in the mtDNA of only Achlya and three other mitochondrial genomes - the yeast Kloeckera africana (Clark-Walker et al. 1981 b), the sporozoan Isospora gondii (Borst et al. 1984), and the linear genome of the ciliate Tetrahymena pyriformis (Goldbach et al. 1978). While both ribosomal cistrons are completely encoded in chloroplast and Achlya repeats, only the L-rRNA is in the Tetrahymena repeat, and only a portion of the L-rRNA is in the Kloeckera repeat.

Intramolecular recombination between inverted repeats in circular eukaryotic DNAs has been detected in the $\mathrm{Sac}$ charomyces cerevisiae $2 \mu \mathrm{m}$ circle (Guerineau et al. 1976), chloroplast genomes (Palmer 1983; Aldrich et al. 1985), and the Achlya mitochondrial genome (Hudspeth et al. 1983; Boyd et al. 1984). Palmer and Thomson (1982) have shown that chloroplast genomes undergo less DNA sequence rearrangement throughout their genomes when an inverted repeat is present, and that the rate of sequence divergence of the repeat itself is less than that of non-repeated sequences (Palmer et al. 1983).

We have extended our studies of Achlya mtDNA to include four strains representing two species. We report here the localization of four region-specific insertions, seven additional gene loci, and an examination of the stability of repeat DNA sequences relative to single copy sequences.

\section{Methods and materials}

Strains. A. ambisexualis 734 and A. heterosexualis $1-4$ and 8-6 were obtained from the Alma Barksdale Collection (New York Botanical Garden, Bronx, NY, USA). The $S$. cerevisiae petite strains encoding ribosomal cistrons were the gifts of P. S. Perlman (Ohio State University, Columbus, $\mathrm{OH}$, USA). Petites containing genic sequences of $\mathrm{COB}$, COI, COIII, ATPase 6, and ATPase 9 were the gifts of A. Tzagoloff (Columbia University, New York, NY, USA). COII sequences in a bacterial plasmid were the gift of $\mathrm{T}$. Fox (Cornell University, Ithaca, NY, USA). 
Table 1. Saccharomyces cerevisiae gene probes

\begin{tabular}{|c|c|c|c|}
\hline Probe & Strain & Source & Sequence reference \\
\hline $\mathrm{COI}$ & DS6/407 & $\begin{array}{l}\text { Hinf/TagI: } \\
\text { base } 130 \text { to } 410 \\
\text { (exon 5) }\end{array}$ & Bonitz et al. (1980) \\
\hline COII & Clone $^{\mathrm{a}}$ & Hinf: base 79 to 430 & $\begin{array}{l}\text { Coruzzi and } \\
\text { Tzagoloff (1979) }\end{array}$ \\
\hline COIII & $\mathrm{DS} / 40$ & $\begin{array}{l}\text { Hinf/PvuII: } \\
\text { base } 341 \text { to } 707\end{array}$ & $\begin{array}{l}\text { Thalenfeld and } \\
\text { Tzagoloff (1980) }\end{array}$ \\
\hline $\mathrm{COB}$ & DS400/A12 & $\begin{array}{l}\text { Hinf: base } 55 \text { to } 533 \\
\text { (exon } 1 \text {, short form) }\end{array}$ & $\begin{array}{l}\text { Nobrega and } \\
\text { Tzagoloff (1980) }\end{array}$ \\
\hline ATPase 6 & DS 14 & $\begin{array}{l}E c o \mathrm{RI} / M b o \mathrm{I}: \\
\text { base } 40 \text { to } 696\end{array}$ & $\begin{array}{l}\text { Macino and } \\
\text { Tzagoloff (1980) }\end{array}$ \\
\hline ATPase 9 & $\mathrm{DS} 400 / \mathrm{A} 3$ & AluI : base 20 to 178 & $\begin{array}{l}\text { Macino and } \\
\text { Tzagoloff (1979) } \\
\text { Hensgens et al. } \\
(1979)\end{array}$ \\
\hline 21SrDNA & $\mathrm{A} 12-48^{\mathrm{b}}$ & $\begin{array}{l}\text { AluI: } \\
\text { base } 698-1867, \\
1965-2658, \\
\text { and } 2709-2975\end{array}$ & $\begin{array}{l}\text { Sor and Fukuhara } \\
\text { (1983) }\end{array}$ \\
\hline $15 S \mathrm{SDNA}$ & BD11 & $\begin{array}{l}\text { AluI/BamHI: } \\
\text { base } 154-720\end{array}$ & $\begin{array}{l}\text { Sor and Fukuhara } \\
(1980) \\
\text { Li et al. (1982) }\end{array}$ \\
\hline Var 1 & A $17-10$ & $\begin{array}{l}\text { Hhal/HaeIII: } \\
\text { base } 199 \text { to } 1217\end{array}$ & $\begin{array}{l}\text { Hudspeth et al. } \\
(1982)\end{array}$ \\
\hline
\end{tabular}

All probes contain only genic or exon sequences with the exception of $303^{\prime}$ flanking var 1 nucleotides. ATPase 6 and 9 probes consist of two fragments and the large rDNA of four fragments

a $2.4 \mathrm{~kb}$ HaellI fragment from wild type $S$. cerevisiae tailed into PstI of pBR 322

b $\omega^{*}$ - strain

Isolation of DNAs. Achlya mycelia grown at room temperature in PYG (Griffin et al. 1974) were harvested in late logarithmic phase from moderately aerated 161 carboys by filtration through a single layer of Miracloth (Calbiochem, La Jolla, CA, USA). Following a 21 water rinse the mycelia were soaked in $10 \mathrm{vol}$ (wet weight) of $100 \mathrm{mM}$ EDTA (pH 7.5) at $4^{\circ} \mathrm{C}$ for $1 \mathrm{~h}$, then collected by filtration through Miracloth, with the excess liquid removed by blotting with absorbent towels. The mycelial mat was ground to a fine powder in liquid nitrogen in 5-10 g aliquots. The frozen powder was resuspended with stirring in $1.0 \mathrm{M}$ sorbitol$0.1 \mathrm{M}$ EDTA-0.1 M Tris ( $\mathrm{pH} 7.5$ ), allowed to thaw at $4^{\circ} \mathrm{C}$, and mtDNA isolated as previously described (Hudspeth et al. 1983). DNAs used for probing Southern blots were isolated as previously described from yeast strains (Hudspeth et al. 1980) and a bacterial plasmid (Maniatis et al. 1982).

Restriction enzyme digestion and gel electrophoresis. Restriction endonucleases were obtained from International Biotechnologies, Inc., New Haven, CT, USA, New England Biolabs, Beverly, MA, USA, Boehringer Mannheim, FRG, or Bethesda Research Laboratories, Gaithersburg, MD, USA. Digestions were carried out in buffers recommended by the manufacturers. Electrophoresis and photography of $0.8 \%$ or $0.6 \%$ agarose and $3.5 \%$ polyacrylamide slab gels were as previously described (Moore et al. 1977; Hudspeth et al. 1983).
Transfer hybridizations. Transfer of restriction fragments from $0.8 \%$ agarose gels to nitrocellulose filters (Schleicher and Schuell, Keene, NH, USA) and hybridization were carried out as described by Southern (1975) with the modifications previously noted (Hudspeth et al. 1983). The gene probes (Table 1) were electroeluted from 3.5\% polyacrylamide gels and nick-translated (Rigby et al. 1977) for $1 \mathrm{~h}$ at $11^{\circ} \mathrm{C}$. Hybridizations were at $40^{\circ} \mathrm{C}$ for the var 1 probe and at $50^{\circ} \mathrm{C}$ for all others.

\section{Results}

\section{Restriction maps}

Physical maps of four Achlya mitochondrial genomes were constructed by restriction endonuclease analysis. Initial analyses of the enzyme digests indicated a variation in individual strains and species both in genome size and in the number and location of restriction sites. To establish the colinearity of the Achlya strains used here and in a prior study (Hudspeth et al. 1983), we derived a minimal composite map for these four heterothallic strains. This map was constructed both by retaining only the 41 restriction sites held in common by all four strains, and by selecting the minimum strain distance between any two common sites (as determined below). Figure 1 compares this common map with the four individual maps, which specify only the 22 additional site variations.

We have used the combination of restriction maps to further refine the minimal and maximal lengths of the inverted repeat, small single copy, and large single copy regions of the Achlya genome previously established (Hudspeth et al. 1983). Our new estimates of the extent of these three genomic regions are based upon the presence of restriction sites in other strains that are more proximal to the repeat boundaries than those previously identified in E-87. These sites are the repeat BstEII sites adjacent to the large single copy region in 1-4 and 8-6; the small single copy $B g l \mathrm{II}$ site adjacent to the repeat in 86 ; and the large single copy $P_{s t} \mathrm{I}$ site adjacent to the repeat in 734 and 8-6. The repeat $B g l I I$ site adjacent to the small single copy region in E-87 is common to all four Achlya strains and remains the most proximal to that single copy boundary.

We assume these site differences to result from a single nucleotide substitution rather than from a repeat length expansion, based on the following considerations. For the variable $B s t$ EII site, we are unable to detect any strain fragment length variation in either the 6.0 or the $3.5 \mathrm{~kb} \mathrm{BglII}$ fragments that cross the large single copy repeat boundaries. The non-repeated $P s t \mathrm{I}$ site lies in the non-variable $3.5 \mathrm{~kb} B g l \mathrm{II}$ fragment. Similarly, for the 8-6 small single copy $B g I I I$ site, the $1.0 \mathrm{~kb} \mathrm{HpaI}$ fragment crossing the small single copy boundary is invariant in strains $734,1-4$, and $8-6$. Calculations using these new boundary sites, in conjunction with the elimination of fragment length variation due to insertions (see below), allow us to describe more accurately the basic Achlya mitochondrial genome. The $49.1 \mathrm{~kb}$ common circle contains two inverted repeats of 9.94-11.24 kb, separated by a small single copy region of $6.23-8.31 \mathrm{~kb}$ and a large single copy region of 20.48-21.01 kb. As discussed below, the common genome may be expanded up to at least $51.8 \mathrm{~kb}$ by optional insertions in each of the three genomic regions. 

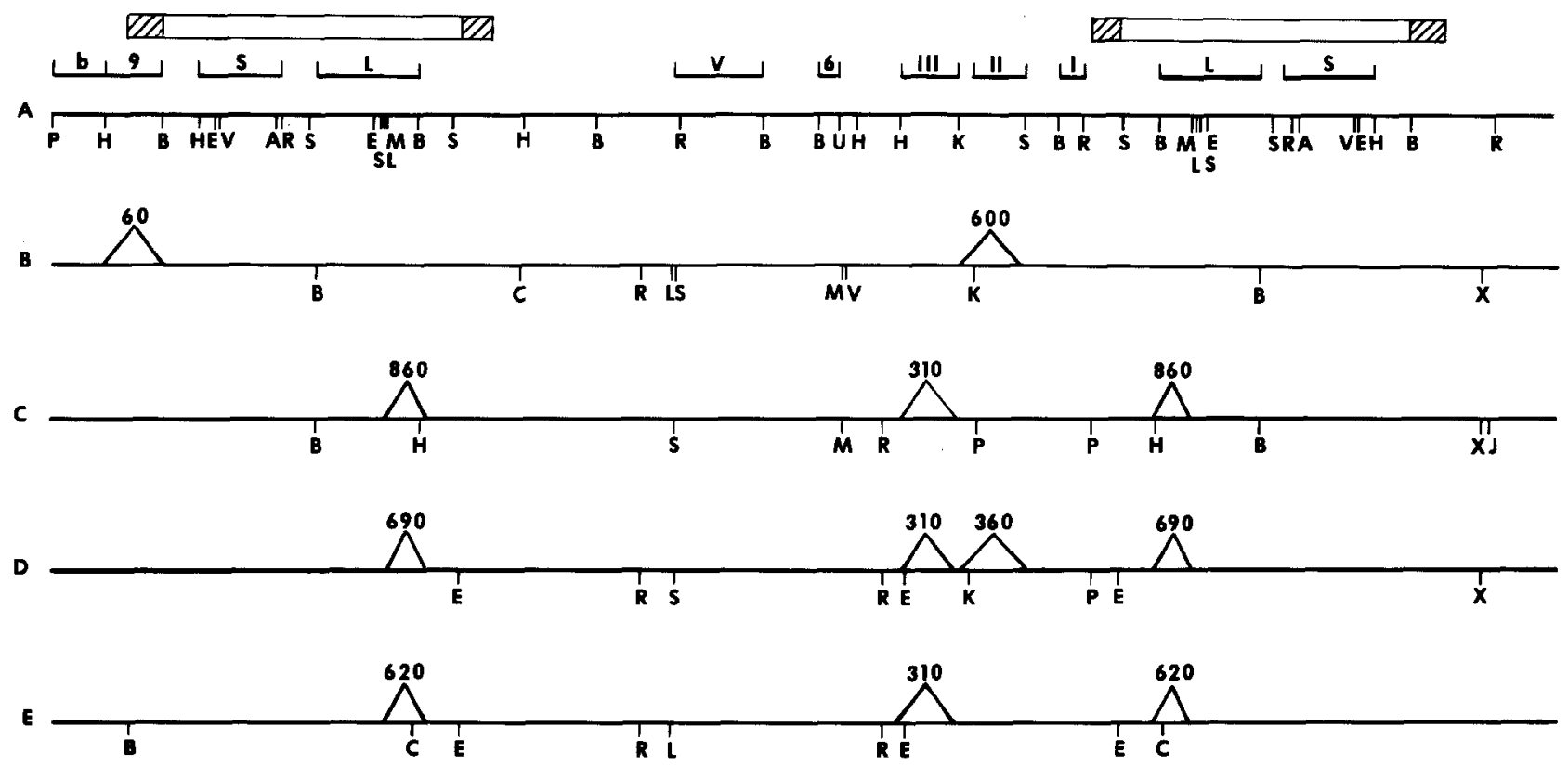

Fig. 1 A-E. Common and individual restriction site maps of Achlya strains. A Summary restriction site map showing only sites common to all four strains. Strains E-87 B, 734 C, 1-4 D, and 8-6 E contain the restriction sites shown plus those of the common map A. Triangles in $\mathbf{B}-\mathbf{E}$ indicate the location and size (in $\mathrm{bp}$ ) of the inserts discussed in the text. The fragments which hybridized to gene probes (see Table 1) are indicated above the summary map. The minimum (open bars) and maximum (hatched ends) lengths of the inverted repeats are shown above the genes. Enzyme abbreviations: A, SstII (SacII); B, BglII; C, ClaI; E, BstEII; H, HpaI; J, BglI; K, KpnI; L, SalI; M, BamHI; P, PstI; R, EcoRI; S, SstI (SacI); U, PvuI; V, PvuII; X, XhoI

\section{Insertions and deletions}

To date the only detailed studies localizing restriction fragment length polymorphisms in fungal mitochondrial genomes are of the ascomycetes Saccharomyces (Sanders et al. 1977), Aspergillus (Earl et al. 1981), and Neurospora (Mannella et al. 1979). We have analyzed the four Achlya genomes presented here by systematic side-by-side comparisons of DNA fragment lengths generated by restriction enzyme sites common to all four strains. The use of common sites allowed us to examine the genomes so that the largest comparison made was limited to approximately $5 \mathrm{~kb}$ fragments. Analyses (repeated at least twice for any set of fragments) using $0.8 \%$ and $0.6 \%$ agarose or $3.5 \%$ polyacrylamide gels allowed us to detect differences as small as $60 \mathrm{bp}$. While we assumed in our analysis the minimum number of insertion or deletion events that best describes DNA fragment length variations, we cannot, of course, exclude the possibility that fragment length variations resulted instead from a larger number of smaller insertions or deletions.

We found only four regions of insertion or deletion events in the genomes. These events were found both in the repeat and in the two single copy regions. Figure 2 illustrates the major fragment length polymorphism revealed by $S s t \mathrm{I}$ digestion, which is localized to the inverted repeat in the $3^{\prime}$ region (see below) of the L-rRNA cistron. Further restriction analyses of the inverted repeat localized the fragment length polymorphism to the region between the $B a m \mathrm{HI}$ and the Bg/II sites, extending from E-87 map coordinates 21.9 to 24.1 and from 73.6 to 75.8 (Hudspeth et al. 1983). These data indicate that the fragment variations relative to E-87 are due to insertions of $0.62 \mathrm{~kb}(8-6), 0.69 \mathrm{~kb}$ $(1-4)$, and $0.86 \mathrm{~kb}(734)$.

Comparison of restriction fragment lengths derived solely from the small single copy region reveals a difference only in strain E-87. The DNA sequence length between the E-87 HpaI (3.4 m.u.) and Bg/II (7.2 m.u.) sites is $1.91 \mathrm{~kb}$, but only $1.85 \mathrm{~kb}$ in the other three strains. Assumption of a single $0.06 \mathrm{~kb}$ insertion in E-87 in this region restores the common restriction enzyme fragment length colinearity throughout the entire small single copy region.

Insertion or deletion events occurring in the large nonrepeated region appear to be more complex. The only detectable events were located between the E-87 HpaI (56.3 m.u.) and SstI (64.5 m.u.) sites, which encompass two $K p n I$ sites in E-87. Distances between these $\mathrm{HpaI}$ and Sst I sites are estimated to be $3.06,3.055,2.85$, and $2.85 \mathrm{~kb}$ in E-87, 1-4, 734, and 8-6, respectively. However, the comparative distance from $H p a \mathrm{I}$ to the first $K p n \mathrm{I}$ site in E-87 is $0.31 \mathrm{~kb}$ less than in the other genomes. The distances from the single or second (when present) $K p n I$ site to the $S s t \mathrm{I}$ site are $1.96 \mathrm{~kb}$ in E-87, $1.92 \mathrm{~kb}$ in $1-4$, and $1.91 \mathrm{~kb}$ in 734 and 8-6. In addition, when two KpnI sites are present, the distance between them also varies, being $0.55 \mathrm{~kb}$ in E-87 and $0.35 \mathrm{~kb}$ in $1-4$. We interpret these data to indicate two independent events. The first is a deletion of $0.31 \mathrm{~kb}$ in the HpaI-KpnI region of E-87 relative to the other strains, and the second is a variable insertion of either $0.6 \mathrm{~kb}(\mathrm{E}-87)$ or $0.36 \mathrm{~kb}(1-4)$, between the first $K p n \mathrm{I}$ site and extending past the second. In the absence of other common sites in the HpaI-Sst I region, however, we cannot exclude the possibility of a single insertion or deletion event bridging the common $K p n I$ site.

\section{Relative stability of genomic regions}

We have analyzed the relative susceptibility to single nucleotide changes of inverted repeat and non-repeated sequences in the mitochondrial genomes of the four Achlya strains using equations ( $\mathrm{Nei}$ and Li 1979; Brown et al. 1979) 

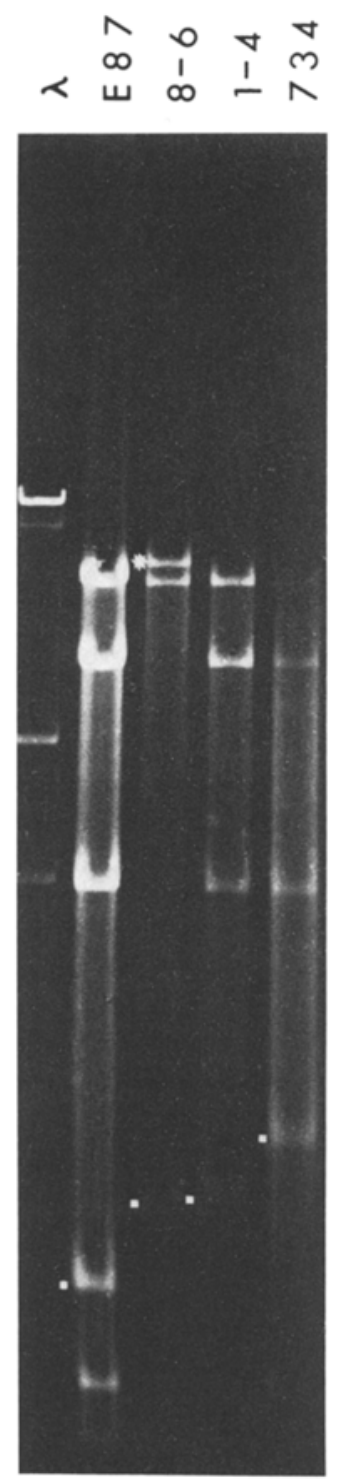

Fig. 2. Repetitive inserts. EthBrstained gel of SstI digests of mtDNA from four Achlya strains. The white squares denote the fragments that map to the same area of the genome yet differ in size (Fig. 1). Other inserts found in the larger $S s t \mathrm{I}$ fragments are unresolvable under these conditions. The 8-6 fragment $(*)$ differs in size due to a deleted site. $\lambda$ denotes bacteriophage lambda DNA digested with Hind III

that relate the number of shared restriction sites to percent sequence divergence. Our analysis is limited to the gain or loss of sites whose recognition sequence requires six specific nucleotides. We have retained the enzymes $B s t$ EII and $B g / \mathrm{I}$ in our analysis since the additional one and five nucleotides in their respective recognition sites are completely degenerate. However, we have excluded from analysis all variant restriction sites that are associated with a known insertion event. These are the repeat insertion $\mathrm{ClaI}$ of strain 8-6, the first large single copy insertion $B s t$ EII of 1-4 and 8-6, and the second $K p n \mathrm{I}$ large single copy insertion of E-87 and 1-4 (Fig. 1). In addition, we have also excluded the previously reported XorII site at E-87 coordinate 68.6 (Hudspeth et al. 1983) as we are unable to confirm its presence with the isoschizomer PvuI. Thus, our analysis is based upon a total of 59 restriction sites, 41 of which are common to all four strains.

The estimated sequence divergence of these Achlya mtDNAs is presented in Table 2. The known intramolecular recombination between repeat elements (Guerineau et al. 1976; Hudspeth et al. 1983; Boyd et al. 1984) has led to the suggestion that the symmetrical nature of nucleotide changes in repeats is due to a copy-choice correction (Ko-
Table 2. Analysis of sequence divergence

\begin{tabular}{llcl}
\hline Region & $\begin{array}{l}\text { Sites } \\
\text { compared }\end{array}$ & $\begin{array}{l}\text { Sites } \\
\text { shared }\end{array}$ & $\begin{array}{l}\text { Percent } \\
\text { sequence } \\
\text { divergence }\end{array}$ \\
\hline Total genome & 59 & 41 & 6.1 \\
Total genome less one repeat & 43 & 28 & 7.2 \\
Total repeat one copy & 16 & 13 & 3.5 \\
Repeat rDNA one copy & 11 & 10 & 1.6 \\
Repeat non-rDNA one copy & 5 & 3 & 8.5 \\
Total single copy & 27 & 15 & 9.8 \\
Large single copy & 21 & 12 & 9.3 \\
Small single copy & 6 & 3 & 11.6 \\
Non-rDNA less one repeat & 32 & 18 & 9.6 \\
Non-rDNA total genome & 48 & 31 & 7.3 \\
\hline
\end{tabular}

Shared sites/compared sites $=\mathrm{S}$; Number of nucleotides recognized $=\mathrm{N} ; \%$ sequence divergence $=-100(\operatorname{lnS}) / \mathrm{N}($ Brown 1979; Nei and Li 1979)

lodner and Tewari 1979; Myers et al. 1982) and is thus independent of sequence divergence. Therefore, we have based our divergence values on those derived from the total genome minus one repeat.

The most striking feature of the divergence analysis is the apparent conservation of repeated sequence DNA relative to single copy DNA. A two to three-fold difference is present in all pairwise combinations except that of 734 with 1-4. To test the significance of these differences we compared the number of variable sites from the two genomic regions of all strains with the number of invariant sites. We scored a variable site change as a single data event when it was absent in at least one of the four genomes. In this manner we were in effect analyzing the overall susceptibility of the genomes to nucleotide substitution rather than the divergence between individual strains. The results indicate an overall divergence of 7.2 percent, with a 2.8 fold difference between repeat (3.5\%) and single copy $(9.8 \%)$ sequences.

This approach also allowed us to address the question of whether the repeat conservation is due to intramolecular recombination events or to the conservative nature of the ribosomal cistrons. We thus compared repeat rDNA (as determined below) with repeat non-rDNA sequences. Although our comparisons are based upon only 11 and 5 restriction sites, respectively, the repeat rDNA value of $1.6 \%$ divergence and the repeat non-rDNA value of $8.5 \%$ divergence strongly argue that the repeat sequence conservation is due to the encoding of rRNA sequences.

\section{Gene loci}

To determine the relationship between coding regions and the observed genome variability, we established the locations of nine potential Achlya mitochondrial genes. These sequences were detected by Southern analysis using as probes the isolated $S$. cerevisiae mtDNA fragments described in Table 1. We attempted to minimize the possibility of cross-hybridization of non-genic regions by radio-labelling $S$. cerevisiae sequences containing only coding regions. The sole exception was the probe for var1, which includes 30 nucleotides of $3^{\prime}$ flanking sequence. Although the degree of homology of different $S$. cerevisiae probes appeared to vary, based on hybridization signal intensity, our hybridizations were done at $50^{\circ} \mathrm{C}$ to provide a criterion low enough 


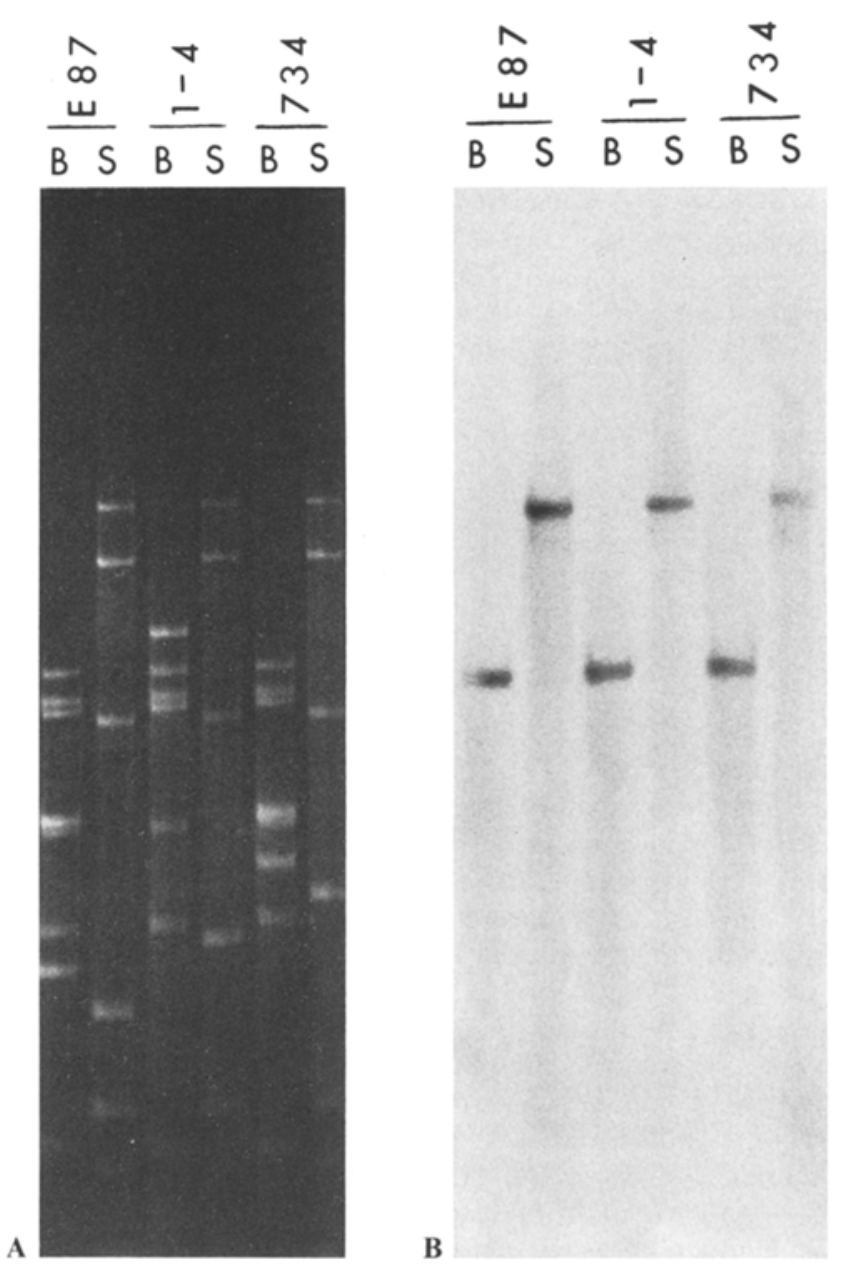

Fig. 3 A, B. Transfer hybridization of mtDNA to localize the COIII gene. A EthBr-stained gel of $B g / \mathrm{II}$ and Sst I digests of three Achlya strains. B Autoradiograph of these DNAs transferred to nitrocellulose and hybridized with yeast mtDNA sequences (Table 1)

to allow hybridization of eight of the nine probes. The stringency at this criterion resulted in hybridization only to specific contiguous Achlya DNA regions. Due to the high A-T content of the var1 probe (Hudspeth et al. 1982), those hybridizations were performed at $40^{\circ} \mathrm{C}$, a criterion required for homologous hybridization of the var1 gene (Zassenhaus et al. 1983). The results of the hybridization of the COIII gene is shown in Fig. 3, and the localization of all the gene probes in Fig. 1.

The gene mapping results for the nine loci assayed show that only the ribosomal cistrons are encoded within the repeat unit. By using specific $5^{\prime}$ and $3^{\prime}$ regions of the yeast L-rRNA probe, we have localized all the homologous $A c h$ lya regions to a repeat $B g / I I$ fragment with the $5^{\prime}$ sequences proximal to the S-rRNA locus. The $3^{\prime}$ sequences extend into the $B a m H I-B g l$ II portion of this fragment, which is also the region of the repeat insertion/deletion event. The S-rRNA probe hybridized to sequences between the HpaI and EcoRI restriction sites near the small single copy region. By assuming reasonable length and sequence conservation with $S$. cerevisiae S-rRNA, and the same polarity as the L-rRNA, the maximum limits for the $5^{\prime}$ and $3^{\prime}$ termini are $154 \mathrm{bp}$ preceding the HpaI site and $966 \mathrm{bp}$ past the EcoRI site. Achlya sequences homologous to the seven $S$. cerevisiae protein encoding probes are found for COI,
II, and III, ATPase 6, and var1 in the large single copy region, and for ATPase 9 and COB in the small single copy sequences.

Examination of insertion/deletion regions showed, surprisingly, that all four regions of variable sequence length were in close proximity to potential genic regions. For the three single copy coding regions, the insertions or deletions need not be within the proximal coding sequences, since the smallest restriction fragment containing these regions of size variation is larger than the entire $S$. cerevisiae coding sequence from which the probe was derived. Furthermore, there has been no prior demonstration in other fungi of optional introns being associated with any of these loci. For instance, in the large single copy DNA the COIII gene maps to the same $H p a I-K p n I$ restriction fragment that contains the $310 \mathrm{bp}$ insert in 734, 1-4, and 8-6. However, the minimal size of this fragment $(2.0 \mathrm{~kb}$ in E-87) is far greater than either the size of the gene probe $(367 \mathrm{bp})$ or the size of the entire $S$. cerevisiae coding sequence $(810 \mathrm{bp}$ ). Similar arguments also apply to the COII and ATPase 9 regions.

The large rRNA cistron has been mapped to fragments adjacent to, and within, the $B a m H I-B g I I$ fragment containing the inverted repeat strain-specific insertion. Although it is tempting to speculate that this insertion is analogous to optional L-rRNA introns described in other fungi (Dujon 1980; Netzker et al. 1982; Burke and RajBhandary 1982), we have not determined the polarity of the hybridization in the insert-containing fragment and cannot ascertain whether the insertion sequences interrupt the L-rDNA sequence or are merely located at its $3^{\prime}$ terminus.

Both COB and COI loci in $S$. cerevisiae contain combinations of multiple introns that can extend the gene loci to over $10 \mathrm{~kb}$ (Grivell et al. 1980, 1982). The probes used in locating homologous Achlya genes were exon regions of less than $0.5 \mathrm{~kb}$. Although both Achlya genes could theoretically extend through proximal insertion regions, too little of the potential genic region has been analyzed thus far to evaluate this possibility.

Finally, we note that the dual orientation of the Achlya mitochondrial genome results in two distinct gene orders. One of these is that illustrated in Fig. 1. The second order results from an inversion of either single copy region through a recombination event between the repeats.

\section{Discussion}

Our detailed restriction analysis of four closely related heterothallic Achlya strains has enabled us to establish a common physical map of their mitochondrial genomes. Reference to this map has provided us with a minimal framework to reflect changes in both restriction endonuclease sites and DNA sequence organization resulting from insertions. The insertions (Fig. 1) not only account for the size variation of the strains, but suggest that insertion events are relatively region-specific. Indeed, though there are seven insertions of different sizes, they occur only in four reasonably welldefined regions of the genome. Previous comparisons of mtDNA physical maps from the ascomycetes Saccharomyces (e.g. Sanders et al. 1977), Aspergillus (Earl et al. 1980), and Neurospora (Mannella et al. 1979) have shown similar region-specific insertions. In many instances these insertions are associated with genic regions, either as introns interrupting coding sequences (e.g. Bonitz et al. 1980; No- 
brega and Tzagoloff 1980), or flanking coding regions (Hudspeth et al. 1984). In Achlya we note that all of the insertions also correlate with genic regions, but we cannot yet define their exact relationship to coding sequences.

Our restriction analyses have allowed us to assess the relative rates of sequence divergence between inverted repeat and single copy sequences. Whether our analysis is based upon pairwise comparisons or the comparison of total site variations involving all four heterothallic strains, the data clearly indicate the relative conservation of inverted repeat sequences. Furthermore, the relative conservation of inverted repeat sequences was still retained when we carried out pairwise comparisons of our four strains with the more distantly related homothallic A. klebsiana (Boyd et al. 1984).

The relative stability of the repeat regions may result from two fundamentally different mechanisms. One is a consequence of the inverted repeat per se, and would result from conversion of a mutation arising in a repeat arm through intramolecular recombination. The other is a consequence of the particular sequences in the repeat arms, and would result from genetic selection. We favor the latter mechanism for two reasons. First, consideration of the effect of intramolecular recombination versus intermolecular recombination on neutral new mutations indicates that the former can affect the rate of fixation, but not, in fact, the probability of fixation over evolutionary time. Second, our data suggest (Table 2, lines 4 vs. 5) that the conservation is limited to the portion of the repeat encoding the rRNAs. However, the paucity of sites in the non-rDNA repeat limits the strength of this conclusion. The same interpretation was also reached in a study of legume chloroplast genomes (Palmer et al. 1983), although those data were also deficient in non-rDNA restriction sites in the repeat. These interpretations are in accord with the well-known relative stability of rDNA, which for mtDNA has been observed in apes and humans (Brown et al. 1982; Cann et al. 1984). However, it is likely that any coding region would appear stable relative to the genome as a whole, suggesting, as our data indicate, that the non-rDNA region of the repeat does not have any other significant coding function.

Analysis of our sequence divergence data at the interspecies level does not conform to the designated speciation for $A$. ambisexualis and $A$. heterosexualis. The interspecies comparisons of strain 734 and 1-4 indicate a lesser degree of divergence than the intraspecies comparison of 734 and E-87. This appears to be a reflection of the close affinity of these species [only three of over 50 Achlya species are heterothallic (Dick 1973)], rather than the inappropriateness of the analysis, since a single site change in each of the pairings restores the species relationships. Furthermore, pairwise comparisons with the homothallic A. klebsiana demonstrate significant divergence. From a systematics viewpoint, then, sequence divergence data in the genus $\mathrm{Ach}$ lya may be useful in distinguishing between two or more closely allied groups and/or between diverse species, but not for differentiating between closely related species.

The detection of Achlya gene loci is based upon heterologous hybridizations using $S$. cerevisiae genic regions of known DNA sequence. These genic probes are devoid of introns and flanking sequence, with the sole exception of the 30 nucleotides at the $3^{\prime}$ end of var1. The reliability of this approach has been well documented by subsequent DNA sequence analysis in several fungi (e.g. Macino and
Tzagoloff 1980) and other lower eukaryotes (de la Cruz et al. 1984). We note only two instances of the inappropriate localization of mitochondrial genes by this technique: A Zea mays COII probe hybridized to Trypanosoma brucei sequence (Johnson et al. 1982 vs. Benne et al. 1983), and an $S$. cerevisiae $\mathrm{COB}$ probe used in Podospora anserina (Wright et al. 1982 vs. Jamet-Vierny et al. 1984). The gene map presented here in one of its two orientations represents the first for a non-ascomycetous filamentous fungus.

Although we have established regions of mitochondrial homology between Achlya and S. cerevisiae coding sequences, we have not shown that these sequences are either transcriptionally or translationally active. This consideration is most important in terms of the ATPase 9 and var1 loci. With the exception of $S$. cerevisiae and some other yeasts (Clark-Walker and Sriprakash 1983), all animal and fungal systems examined encode the functional mitochondrial ATPase subunit 9 in the nuclear genome. In Neurospo$r a$ and Aspergillus (Van den Boogaart et al. 1982; Brown et al. 1984), however, in spite of the functional gene's being nuclear, undisturbed ATPase 9 sequences are present in the mitochondrial genomes and are only minimally, if at all, transcribed (de Vries et al. 1983). Mitochondrial ribosomal proteins also appear to be nuclearly encoded with the exceptions of S-5 in Neurospora and Aspergillus (La Polla and Lambowitz 1981) and var1 in S. cerevisiae and other yeasts (Terpstra et al. 1979; Clark-Walker and Sriprakash 1983). To date the only mitochondrial homologies to either ATPase 9 or to var1 sequences reported outside of the ascomycetes have been seen in the basidiomycete genus Coprinus (Weber et al. 1986).

Acknowledgements. We thank C. William Birky (Ohio State University) for stimulating discussions, Jeffrey D. Palmer for critically reading the manuscript, Jennifer Cornell for secretarial help and David Bay for photography. This work was supported by NIH grant GM-26546 (LIG) and Department of Energy Grant DE-FG02-80-ER10125 (The University of Michigan MESH).

\section{References}

Aldrich J, Cherney B, Merlin E, Williams C, Mets L (1985) Recombination within the inverted repeat sequences of the Chlamydomonas reinhardii chloroplast genome produces two orientation isomers. Curr Genet 9:233-238

Benne R, DeVries BF, Van den Burg J, Klaver B (1983) The nucleotide sequence of a segment of Trypanosoma bruicei mitochondrial maxi-circle DNA that contains the gene for apocytochrome $b$ and some unusual unassigned reading frames. Nucl Acids Res 11:6925-6941

Bonitz SG, Coruzzi G, Thalenfeld BE, Tzagoloff A, Macino G (1980) Assembly of the mitochondrial membrane system. Structure and nucleotide sequence of the gene coding for subunit 1 of yeast cytochrome oxidase. J Biol Chem 255:11927-11941

Borst P, Overdulve JP, Weyers PJ, Fase-Fowler F, Van Den Berg $\mathrm{M}$ (1984) DNA circles with cruciforms from Isospora (Toxoplasma) gondii. Biochim Biophys Acta $781: 100-111$

Boyd DA, Hobman TC, Gruenke SA, Klassen GR (1984) Evolutionary stability of mitochondrial DNA organization in Achlya. Can J Biochem Cell Biol 62:571-576

Brown WM, George Jr M, Wilson AC (1979) Rapid evolution of animal mitochondrial DNA. Proc Natl Acad Sci USA 76:1967-1971

Brown WM, Prager EM, Wang A, Wilson AC (1982) Mitochondrial DNA sequence of primates: tempo and mode of evolution. J Mol Evol 18:225-239

Brown TA, Ray JA, Waring RB, Scazzochio C, Davies RW (1984) 
A mitochondrial reading frame which may code for a second form of ATPase subunit 9 in Aspergillus. Curr Genet 8:489-492

Browning KS, RajBhandary UL (1982) Cytochrome oxidase subunit III gene in Neurospora crassa mitochondria. Location and sequence. J Biol Chem 257:5253-5256

Burke JM, RajBhandary UL (1982) Intron with the large rRNA gene of $N$. crassa mitochondria: A long open reading frame and a consensus sequence possibly important in splicing. Cell $31: 509-520$

Cann RL, Brown WM, Wilson AC (1984) Polymorphic sites and the mechanism of evolution in human mitochondrial DNA. Genetics 106:479-499

Clark-Walker GD, Sriprakash KS (1983) Map location of transcripts from Torulopsis glabrata mitochondrial DNA. EMBO J 2:1465-1472

Clark-Walker GD, McArthur CR, Daley DJ (1981 a) Does mitochondrial DNA length influence the frequency of spontaneous petite mutants in yeasts? Curr Genet 4:7-12

Clark-Walker GD, McArthur CR, Sriprakash KS (1981 b) Partial duplication of the large ribosomal RNA sequence in an inverted repeat in circular mitochondrial DNA from Kloeckera africana. Implications for mechanisms of the petite mutation. $\mathbf{J} \mathrm{Mol}$ Biol 147:399-415

Coruzzi G, Tzagoloff A (1979) Assembly of the mitochondrial membrane system: DNA sequence of subunit 2 of yeast cytochrome oxidase. J Biol Chem 254:9324-9330

de la Cruz VF, Nickelmann N, Simpson L (1984) Sequence of six genes and several open reading frames in the kinetoplast maxicircle DNA of Leishmania tarentolae. J Biol Chem 259:15136-15147

de Vries H, de Jonge JC, Arnberg A, Peijnenburg AACM, Agsteribbe E (1983) The expression of the mitochondrial genes for subunit 1 of cytochrome $c$ oxidase and for an ATPase proteolipid in Neurospora crassa: nucleotide sequence and transcript analysis. In: Scheweyen RJ, Wolf K, Kaudewitz F (eds) Mitochondria 1983: Nucleo-mitochondrial interactions. Walter de Gruyter, Berlin, pp 343-356

Dick MW (1973) Saprolegniales. In: Ainsworth GC, Sparrow FK, Sussman AS (eds) The fungi. An advanced treatise. Academic Press, New York, pp 138-139

Dujon B (1980) Sequence of the intron and flanking exons of the mitochondrial $21 \mathrm{~S}$ rRNA gene of yeast strains having different alleles at the omega and rib-1 loci. Cell 20:185-187

Dujon B (1983) Mitochondrial genes, mutants and maps: A review. In: Schweyer RJ, Wolf K, Kaudewitz F (eds) Mitochondria 1983: nucleo-mitochondrial interactions. Walter de Gruyter, Berlin, pp 4-11

Earl AJ, Turner G, Croft JH, Dales RBG, Lazarus CM, Lunsdorf H, Kuntzel H (1981) High frequency transfer of species specific mitochondrial DNA sequences between members of the Aspergillaceae. Curr Genet 3:221-228

Garber RC, Yoder OC (1984) Mitochondrial DNA of the filamentous ascomycete Cochliobolus heterostrophus. Characterization of the mitochondrial chromosome and population genetics of a restriction enzyme polymorphism. Curr Genet 8:621-628

Goldbach RW, Borst P, Bollen-deBoer JE, van Bruggen EFJ (1978) The organization of ribosomal RNA genes in the mitochondrial DNA of Tetrahymena pyriformis strain ST. Biochim Biophys Acta 521:169-186

Griffin DH, Timberlake WE, Cheney JC (1974) Regulation of macromolecular synthesis, colony development, and specific growth rate of Achlya bisexualis during balanced growth. J Gen Microbiol 80:381-388

Grivell LA, Arnberg AC, Hensgens LAM, Roosendaal E, Van Ommen GJB, VanBruggen EFJ (1980) Split genes on yeast mitochondrial DNA: Organization and expression. In: Kroon AM, Saccone C (eds) The organization and expression of the mitochondrial genome. Elsevier, Amsterdam, pp 37-49

Grivell LA, Hensgens LSM, Osinga KA, Tabak HF, Boer PH, Crusius JBA, van der Laan JC, de Haan M, van der Horst G, Evers RF, Arnberg AC (1982) RNA processing in yeast mitochondria. In: Slonimski P, Borst P, Attardi G (eds) Mitochondrial genes. Cold Spring Harbor Laboratory, Cold Spring Harbor, New York, pp 225-239

Guerineau M, Grandchamp C, Slonimski PP (1976) Circular DNA of a yeast episome with two inverted repeats: Structural analysis by a restriction enzyme and electron microscopy. Proc Natl Acad Sci USA 73:3030-3034

Hensgens LAM, Grivell LA, Borst P, Bos JL (1979) Nucleotide sequence of the mitochondrial structural gene for subunit 9 of yeast ATPase complex. Proc Natl Acad Sci USA 76:1663-1667

Hintz WE, Mohan M, Anderson JB, Horgen PA (1985) The mitochondrial DNAs of Agaricus: heterogeneity in A. bitorquis and homogeneity in A. brunnescens. Curr Genet 9:127-132

Hudspeth MES, Ainley WM, Shumard DS, Butow RA, Grossman LI (1982) Location and structure of the var1 gene on yeast mitochondrial DNA: Nucleotide sequence of the 40.0 allele. Cell 30:617-626

Hudspeth MES, Shumard DS, Tatti KM, Grossman LI (1980) Rapid purification of yeast mitochondrial DNA in high yield. Biochim Biophys Acta 610:221-228

Hudspeth MES, Shumard DS, Bradford CJR, Grossman LI (1983) Organization of Achlya mtDNA: A population with two orientations and a large inverted repeat containing the rRNA genes. Proc Natl Acad Sci USA 80:142-146

Hudspeth MES, Vincent RD, Perlman PS, Shumard DS, Treisman LO, Grossman LI (1984) The expandable var1 gene of yeast mitochondrial DNA : In-frame insertions can explain the strainspecific protein size polymorphisms. Proc Natl Acad Sci USA $80: 3148-3152$

Jamet-Vierny C, Begel O, Belcour L (1984) A $20 \times 10^{3}$-base mosaic gene identified on the mitochondrial chromosome of Podospora anserina. Eur J Biochem 143:389-394

Johnson BJB, Hill GC, Fox TD, Stuart K (1982) The maxicircle of Trypanosoma brucei kinetoplast DNA hybridizes with a mitochondrial gene encoding cytochrome oxidase subunit II. Mol Biochem Parasitol 5:381-390

Kawano S, Suzuki T, Kuroiwa T (1982) Structural homogeneity of mitochondrial DNA in the mitochondrial nucleoid of Phy sarum polycephalum. Biochim Biophys Acta 696:290-298

Klimczak LJ, Prell HH (1984) Isolation and characterization of mitochondrial DNA of the oomycetous fungus Phytophthora infestans. Curr Genet 8:323-326

Kolodner R, Tewari KK (1979) Inverted repeats in chloroplast DNA from higher plants. Proc Natl Acad Sci USA 76:41-45

LaPolla RJ, Lambowitz AM (1981) Mitochondrial ribosome assembly in Neurospora crassa: Purification of the mitochondrially synthesized ribosomal protein, S-5. J Biol Chem 256:7064-7067

Li M, Tzagoloff A, Underbrink-Lyon K, Martin NC (1982) Identification of the paromomycin-resistant mutation in the 15S rRNA gene of yeast mitochondria. $\mathrm{J}$ Biol Chem 257:5921-5928

Macino G (1980) Mapping of mitochondrial structural genes in Neurospora crassa. J Biol Chem 255:10563-10565

Macino G, Tzagoloff A (1979) Assembly of the mitochondrial membrane system. The DNA sequence of a mitochondrial ATPase gene in Saccharomyces cerevisiae. J Biol Chem 254:4617-4623

Macino G, Tzagoloff A (1980) Assembly of the mitochondrial membrane system: Sequence analysis of a yeast mitochondrial ATPase gene containing the oli-2 and oli-4 loci. Cell 20:507-517

Maniatis T, Fritsch EF, Sambrook J (1982) Molecular cloning. A laboratory manual. Cold Spring Harbor Laboratory, Cold Spring Harbor, New York, pp 90-91

Mannella CA, Pittenger TH, Lambowitz AM (1979) Transmission of mitochondrial deoxyribonucleic acid in Neurospora crassa sexual crosses. J Bacteriol 137:1449-1451

Moore KH, Johnson PH, Chandler SEW, Grossman LI (1977) A restriction endonuclease cleavage map of mouse mitochondrial DNA. Nucl Acids Res 4:1273-1289

Myers AM, Grant DM, Rabert DK, Harris EH, Boynton J, Gil- 
ham NW (1982) Mutants of Chlamydomonas reinhardtii with physical alterations in their chloroplast DNA. Plasmid 7:133-151

Nei M, Li WH (1979) Mathematical model for studying genetic variation in terms of restriction endonucleases. Proc Natl Acad Sci USA 76:5269-5273

Netzker R, Kochel HG, Basak N, Kuntzel H (1982) Nucleotide sequence of Aspergillus nidulans mitochondrial genes coding for ATPase subunit 6, cytochrome oxidase subunit 3, seven unidentified proteins, four tRNAs and L-rRNA. Nucl Acids Res 10:4783-4794

Nobrega FG, Tzagoloff A (1980) Assembly of the mitochondrial membrane system: DNA sequence and organization of the cytochrome $b$ gene in Saccharomyces cerevisiae D 273-10 B. J Biol Chem 255:9828-9837

Palmer JD (1983) Chloroplast DNA exists in two orientations. Nature 30:92-93

Palmer JD (1985) Evolution of chloroplast and mitochondrial DNA in plants and algae. In: MacIntyre RJ (ed) Monographs in evolutionary biology: molecular evolutionary genetics. Plenum Publishing, New York, NY, pp 13-14

Palmer JD, Thomson WF (1982) Chloroplast DNA rearrangements are most frequent when a large inverted repeat sequence is lost. Cell 29:537-550

Palmer JD, Singh GP, Pillay DTN (1983) Structure and sequence evolution of three legume chloroplast DNAs. Mol Gen Genet 190:13-19

Rigby PWJ, Dieckman M, Rhodes C, Berg P (1977) Labeling deoxyribonucleic acid to high specific activity in vitro by nick translation with DNA polymerase I. J Mol Biol 113:237-251

Sanders JPM, Heyting C, Verbeet MP, Meijlink CPW, Borst P (1977) The organization of genes in yeast mitochondrial DNA. III. Comparison of the physical maps of the mitochondrial DNAs from three wild-type Saccharomyces strains. Mol Gen Genet 157:239-261

Sebald W, Hoppe J, Wachter E (1979) Amino acid sequence of the ATPase proteolipid from mitochondria, chloroplasts, and bacteria (wild-type and mutants) In: Quagliariello E, Palmieri F, Papa S, Klingenberg M (eds) Function and molecular aspects of biomembrane transport. Elsevier/North Holland, Amsterdam, pp 63-74

Sor F, Fukuhara H (1980) Biologie Moleculaire - Sequence nuclotidique du gene de 1'ARN ribosomique $15 \mathrm{~S}$ mitochondrial de la levure. CR Acad Sci Paris, Ser B 291:933-936

Sor R, Fukuhara H (1983) Complete DNA sequence coding for the large ribosomal RNA of yeast mitochondria. Nucl Acids Res 11:339-348

Southern EM (1975) Detection of specific sequences among DNA fragments separated by gel electrophoresis. J Mol Biol 98:503-517

Specht CA, Novotny CP, Ulrich RC (1983) Isolation and characterization of mitochondrial DNA from the basidiomycete $S c h i-$ zophyllum commune. Exp Mycol 7:336-343

Terpstra P, Zanders E, Butow RA (1979) The association of var1 with the $38 \mathrm{~S}$ mitochondrial ribosomal subunit in yeast. J Biol Chem 254:12653-12661

Thalenfeld BE, Tzagoloff A (1980) Assembly of the mitochondrial membrane system: Sequence of the oxi2 gene of yeast mitochondrial DNA. J Biol Chem 255:6173-6180

Van den Boogaart P, Samallo J, Agsteribbe E (1982) Similar genes for a mitochondrial ATPase subunit in the nuclear and mitochondrial genomes of Neurospora crassa. Nature 298:187-189

Weber CA, Hudspeth MES, Moore GP, Grossman LI (1986) Analysis of the mitochondrial and nuclear genomes of two basidiomycetes, Coprinus cinereus and Coprinus stercorarius. Curr Genet 10:(in press)

Wright RM, Horrum MA, Cummings DF (1982) Are mitochondrial structural genes selectively amplified during senescence in Podospora anserina? Cell 29:505-515

Zassenhaus HP, Farrelly F, Hudspeth MES, Grossman LI, Butow RA (1983) Transcriptional analysis of the Saccharomyces cerevisiae mitochondrial var1 gene: Anomalous hybridization of RNA from AT-rich regions. Mol Cell Biol 3:1615-1624

Communicated by R. B. Goldberg

Received September 15, 1985 